\title{
Strategies of Households Resilience in Adapting to Challenges in Turkana County
}

\author{
Loice Yodah $^{1}$, Karanja Anthony ${ }^{2}$, Pius Kihara ${ }^{3}$ \\ ${ }^{1}$ Department of Mathematics, Multimedia University of Kenya, Nairobi, Kenya \\ ${ }^{2}$ Department of Mathematics, School of Science, Multimedia University of Kenya, Nairobi, Kenya \\ ${ }^{3}$ Department of Financial and Actuarial Mathematics, Technical University of Kenya, Nairobi, Kenya \\ Email address: \\ lyodah@yahoo.com(L. Yodah.),karanjah@mmarau.ac.ke(K. Anthony), piuskaranja@yahoo.com (P.Kihara)

\section{To cite this article:} \\ Loice Yodah, Karanja Anthony, Pius Kihara. Strategies of Households Resilience in Adapting to Challenges in Turkana County. American \\ Journal of Theoretical and Applied Statistics. Vol. 9, No. 5, 2020, pp. 228-237. doi: 10.11648/j.ajtas.20200905.16
}

Received: August 2, 2020; Accepted: September 22, 2020; Published: October 12, 2020

\begin{abstract}
Turkana County experiences re-occurring drought and conflict leading to an increased dependency ratio, injuries, both physical and emotional as well as displacement. This study, using Resilience Index Measurement, Analysis is to determine which factors have the capability to maximize resilience in livelihoods by minimizing the effect of the shock by looking at different ways of how livelihood contributes to household's coping strategies and capacity during the calamity. Data used in this study was obtained through quantitative method where a sample $(\mathrm{n} \geq 384)$ was drawn from the target population by random sampling from the data collected between 2015 and 2016. Factor loading analysis was done to establish the weights of each resilience component. RIMA model has shown the ability to be an appropriate tool that can deal with both linear and nonlinear regression concepts. The overall Resilience Index of Turkana county was 0.0457 and that gender to some extent is contributing factor in determining the resilience index. The household head for Pastoral category were between 24-41 years, which is young with 28 years as the average age. Access to market facility determines the kind of what livelihood activity individual engages in at $79 \%$. Access to credit significantly affects Resilience of an individual $(p<0.1)$ thus contributing to diversity in choosing livelihood negatively. Remittances have a negative effect on the fishery and farming livelihoods by $7 \%$.
\end{abstract}

Keywords: Determinants of Livelihood Strategy, Resilience Index of a Household, Coping Strategies of Households

\section{Introduction}

The resilience concept came up in ecological literature to find out more on the complex set up in the socio-economic aspect [1]. During that time, engineering and ecological resilience were the two main variants [2]. Engineering resilience, according to [3] focuses on the steady state after a perturbation. Ecological resilience can be measured as the magnitude of the perturbation that can be absorbed by the system before falling from one state to a lower one [4] and engineering resilience, that can be measured as the speed at which the system returns to the stable point or trajectory following a perturbation $[3,2]$. This aspect of resilience is used by the engineers in developing optimal designs as it deals with efficiency, constancy, and predictability known as "fail-safe" designs. The approach has been included in early warning systems in food security analysis by looking at basic units of a household in food security analysis recently. It is notable that ecological resilience has come out in economics to find out of multi-stable state due to path-dependency [5], "chreodic" development [6] and making of numerous increase return to scale [7]. Initially, the concept of development in rural and priorities in terms of plans and applications was not a major concern until this perception was changed by research concept paper by [8] called "Sustainable livelihoods" which gave a new strategy as part of its attraction and existence of different developments, changes and measure. The idea was perceived as that being knowledgeable and having background knowledge, conceptual, practical and organizational roots [9]. British development organizations (for example, IDS, ODI and DFID, among others, view "Livelihoods thinking" as the afterbirth of what was welcomed by many prominent Non-Governmental Organizations (for example, Oxfam, CARE,) and organizations for development organizations (for example, FAO, UNDP) 
whose mandate still lasts for good reasons [10].

Humanitarian and development organizations have used various definitions of resilience which seems different but share the same aspects such as: recovery ability after a shock, capacity to bear changes in the environment; and how to adapt to the new life brought about by the disaster. It therefore means that a household's resilience is dependent on what the households own (assets), activities that brings incomes, public utilities and services, income generating activities, public services and other sources of services provided by the state or other actors. According to [11], resilient households could also be a forward looking and invest in children's education and community-based risk sharing arrangement. Resilience is defined as a capacity that ensures stressors and shocks do not have long-lasting adverse development consequences [12]. Resilience Measurement Technical Working Group2 (RMTWG) defined resilience as "a capacity that ensures stressors and shocks do not have long-lasting adverse development consequences" [13]. The definitions make strength on the various aspects of being stable that is possible to be used as substitute to dimensions which reflects on the early concepts of resilience or different feeling of nature [14]. It can also be referred to as the magnitude of disturbance that can be absorbed before the system re-defines its structure by changing the variables and processes that control behavior [15]. Over the years, inadequate rainfall has resulted to chronic food insecurity and prolonged cyclic droughts in the Arid and SemiArid Lands (ASALs). There has been therefore increased need to identify specific solutions to allow the in-need population group in the prolonged crisis to widen their ability in order to be able to bear the shocks brought by the disaster and broaden their resilience to the dynamics of life. An ideal bridge between direct and indirect measures of resilience is represented by the Resilience Capacity Index (RCI), which can be employed as to predict food security [16]. Resilience is an intrinsically dynamic concept that exhibits complex and farfrom-equilibrium dynamics [1] and as such requires a dynamic analytical framework. The Amer 28 Psychiatric Association did not list any measures of resilience in the recent textbook of psychiatric measures [17].

This research therefore aims to measure resilience of a given household through Resilience Index measurement Analysis (RIMA), [18] which has demonstrated to be an effective and can deal with linear and nonlinear regression concepts compared to the Jew, Green, and Kroger scale which mostly focused on internal characteristics of an individual rather than factors outside of the individual [19]. RIMA investigations showed that it's more efficient, accurate and robust in complex analysis. This study aims to assess coping, prediction and recuperation mechanisms from the pressures and shocks of at-risk households in Turkana County.

\section{The RIMA Model}

The study used an updated version of the resilience framework developed by [18]. RIMA concept reports the simple equations that fit in the resilience analysis into analytical framework. This approach uses household as the simple unit of analysis and food security analysis as the outcome variable. Resilience and outcome relation are presented as in the equation 1 below [18].

$$
X_{i}^{1}=f\left(P r_{l}^{0}, P_{s h}^{0}, R I_{i}^{0}\right)
$$

Where $\mathrm{Xi}$ is food security outcome, Pr is the probability of experiencing a natural disaster as a result of the physical location where the household lives, Psh is the probability of undergoing through a shock based on the livelihoods characteristics of a household suffering from a shock due to a disaster, RIi is the resilience Index of the household.

The equation 1 above illustrates that the outcome variable for the subsequent years is determined by the initial year value year 0 whether a disaster occurred or not occurred. The time variable is the difference between initial year and the subsequent year, say 1 as per the equation, where the difference between 1 and 0 as the time when a shock occurs. It therefore implies that the intensity of $\mathrm{X}$ (outcome) in time $t+1$ depends on whether something happened to the household. This implies that the intensity of an outcome $\mathrm{X}$ in time $\mathrm{t}+1$ depends on if nothing happens to a household, in time t. For example:

$$
X_{t+1, i}=f\left(X+\varepsilon_{t, i}\right)
$$

for $\mathrm{t}=1, \mathrm{~T}$ and $\mathrm{i}=1, \ldots, \mathrm{I}$, is how the outcome variable in time $\mathrm{t}+1$ is a function of itself in time and $\varepsilon_{t, i}$ as the error term.

For Linear fixed effects models, in $\mathrm{i}$ observations and $\mathrm{t}$ as the time intervals

$$
\begin{gathered}
x_{t+1, i}=\beta x+\left(\alpha_{h} y+\alpha_{l} R_{i}\right)+\left(\gamma_{s} S H_{j}+\gamma_{r} R I_{t, i}+\right. \\
\left.\gamma_{r s} R I S H\right)+\varepsilon_{t, i}
\end{gathered}
$$

The equation 3 above have three parts where $\beta x_{j}$ explains the outcome value at time $t ; X_{j}$ is the valued assumed by time invariant matrix of the household traits; $\mathrm{R}_{\mathrm{i}}$ is the household's residential smallest geographical location time-invariant matrix traits; $\left(\alpha_{\mathrm{h}} \mathrm{y}_{\mathrm{i}}+\alpha_{1} \mathrm{R}_{\mathrm{j}}\right)$ represents the effect on the individual. $\left(\gamma_{\mathrm{s}} \mathrm{SHj}+\gamma_{\mathrm{r}} \mathrm{RIt}, \mathrm{i}+\gamma_{\mathrm{rs}} \mathrm{RISH}\right)$ is the relationship between Resilience and shock where $\mathrm{SH}_{\mathrm{j}}$ is the $\mathrm{j}$ shock occurring; $\mathrm{RI}_{\mathrm{t}, \mathrm{i}}$ is the resilience of the household $\mathrm{i}$ in time $\mathrm{t}$; $\mathrm{SH}$ is the effect of the shock $\mathrm{j}$ over the resilience of the household (i.e to what extent is $\mathrm{SHj}$ going to change $\mathrm{RI}_{\mathrm{t}, \mathrm{i}} ; \varepsilon_{\mathrm{t}, \mathrm{i}}$ is the error term. The model illustrates the factors used to determine the food security of a given household whenever a household experiences a shock. In order to classify a household as food secure, the previous values of the food outcome assumed, and household assets and abilities play a major role. Theoretically, assets owned by a household may have an influence on how the household responds to a shock whenever it occurs. An environment where the household lives also may influence on the response to a shock as well as beneficial and enabling environment facilitates response to disaster thus may reduce the intensity of the influence. However, well off household can also experience severe shock when they do not receive a response from the authorities or irrelevant response mechanism in good time as 
the loss would be too huge (or wrong reposes as well) at a given time invariant. The constant term illustrates how household's resilience is affected by the shock.

$\left(\gamma_{\mathrm{s}} \mathrm{SH}_{\mathrm{j}}+\gamma_{\mathrm{r}} \mathrm{RI}_{\mathrm{t}, \mathrm{i}}+\gamma_{\mathrm{rs}} \mathrm{RISH}\right)$ shows the effect of a shock to household resilience. $\mathrm{SH}$ is the measure of shock a measure of how a shock affects the outcome variable in time $\mathrm{t}$ for $\mathrm{i}=1,2,3 \ldots . . \mathrm{SH}$ is a measure of how a shock affects $x_{t+1}$, ; RI represents the households' resilience. The former vector observations may or may not affect $X$ negatively, the latent vector observations will show negative effects on X. Lastly RISH tells how that specific shock can affect the resilience of the household (reducing or compromising). From equation (2), $\mathrm{X}$ can reduce significantly if a household experience a shock in replicated number of years i.e yearly. These factors depend on time (time variant). The study therefore produced conceptual framework through fixed effect model to better help

$$
\left(X_{t+1, i}-X_{t, i}\right)=\left[\alpha_{h}\left(Y_{i, t}-\bar{Y}_{l}\right)+\alpha_{l}\left(L_{i, t}-\bar{L}_{l}\right)\right]+\left[\gamma_{s}\left(\partial S H_{j}\right)+\gamma_{r}\left(\partial R I_{t, i}\right)+\gamma_{r s}(\partial R I S H)\right]+\partial \varepsilon_{t, i}
$$

Where $\bar{X}_{\iota}=\frac{1}{T} \sum_{t=1}^{T} X_{i}$ and $\overline{L_{l}}=\frac{1}{T} \sum_{t=1}^{T} L_{i} . \mathrm{X}$ and $\mathrm{L}$ are both time dependent hence the effect is ruled out hence removed from equation 5:

$$
\partial x_{i}=\gamma_{s}\left(\partial S H_{j}\right)+\gamma_{r}\left(\partial R I_{t, i}\right)+\gamma_{r s}(\partial R I S H)
$$

In order to understand the how varied the components are when a shock occurs, equation 7 below is used:

$$
\frac{\partial \Delta x_{i}}{\partial S H}=\partial R I_{i}+\partial R I S H_{i}
$$

The equation shows that the effect of a shock on food security component $(\mathrm{X})$ is the sum of the household's resilience index and effect of the shock on resilience. The effect of a shock (SH) and Resilience Index (RI) can be better understood by mitigating the effect of the shock on the $\mathrm{X}$ and comparing it with RI.

Measuring (7) allows several policy indications and gives the opportunity to measure the "resilience gap", i.e.: the distance to fill the gap needed to make a household ready to cope with shocks.

To determine the resilience approach more clearly and how related it is to the other approaches, the study applied the resilience interaction with vulnerability as illustrated in equation 8. In this case, Vulnerability of how a household is [i] expressed as a representation and resilience to risk function.

$$
w_{i}=f\left(\text { exposure }_{\text {risk }}, R I_{i}\right)
$$

FAO defines resilience as the ability of the household to return to its original state after experiencing a shock. In line with this definition, the resilience of a given household/individual is more of ability and nothing else. Hence various aspects are important as a recovery mechanism of a household once $d$ faced with different challenges. With respect to this idea, resilience is more a matter of capacity than anything else. understand the relationship between food security and measurement model. The Fixed effect model approach assumed the individual effect are unobserved, varies with time and specific group constant as used in the regression model under the strict exogenous assumption $(\mathrm{E}[\varepsilon \mid \mathrm{X}=0])$ that can be attributed to independent variables.

Error attributed to this effect can be illustrated as:

$$
m_{i t}=\beta_{h}+\varepsilon_{t, i}
$$

If we take $\left(\beta_{h} X_{i}+\beta_{l} L_{i}\right)$ to be correlated with the $\left(\alpha_{h}\right)$, time-invariant while we still assume that it is uncorrelated while continuing to assume that it is uncorrelated with $\left(\varepsilon_{t, i}\right)$.

Fixed effect model solves the correlation effect between the individual effect and the independent variables through reducing the variables by within transformation:

\section{Methodology}

The study is aimed at assessing the coping, prediction and recuperation mechanisms from pressures and shocks of atrisk households in Turkana County. This is done by establishing the key determinants of livelihood and coping strategies. The study also estimates the resilience index of a household in Turkana County using the RIMA model.

\subsection{Study Design}

The study is aimed at assessing the coping, prediction and recuperation mechanisms from the pressures and shocks of at-risk households in Turkana County. This is done by establishing the key determinants of livelihood and coping strategies. The study also estimates the resilience index of a household in Turkana County using the RIMA model. In achieving this, a secondary data analysis of the already collected data from the Kenya National Bureau of statistics was done to investigate the characteristics associated with social and economic dimensions of the people living within Turkana county. Households were randomly selected from the total sampled households taking into consideration the sub-counties, livelihood zones, gender and household head for the period of between 2015 and 2016. The population for this study consisted of all households residing within Turkana county between May 2015 and May 2016. The subcounties included: Turkana North, Turkana Central, Turkana East, Turkana West, Turkana South and Loima. Agropastoral, Farming, Fishing, Pastoral and Urban were the main livelihood categories used for the study. The county human population during the Kenya population and Housing Census of 2009 stood at 855,399 . The Proportional allocation method was to distribute the sample across the sub-counties, then cluster sampling method was used to obtain the sample within the sub-counties where livelihoods zones were considered as clusters and the primary sampling units were households. Households were then selected through a 
household list using a systematic random sampling method in each cluster. The main analysis component of this study was households, which is the primary sampling unit. The study applied the Taro Yamane (1973) sample size formulae to obtain a sample size of 384 households from the targeted population with a 95\% confidence level and the error margin of 5\%. Taro Yamane sample size is as given below:

$$
n=\frac{N}{1+N(e)}
$$

Where $\mathrm{n}$ signifies the sample size, $\mathrm{N}$ is the total population of study and $\mathrm{e}$ is the allowable error (\%).

The sampling effectiveness and adequacy was established against the 0.5 preferred value. Structural equation modeling method was used to help in determining the factors affecting households' resilience to food insecurity, a revision to [18] proposed methodology.

This approach lies mainly on the ability of the household to earn a living and thus the abilities were evaluated with regards to activities that generate income, access to basic services, properties owned and access to social safety nets. This study used principal components/factor analysis for continuous variables and optimal scaling multivariate techniques to estimate the latent variables (ABS, IFA, AA, NAA, S, AC and SSN) using the available indicators of each latent dimension separately as shown in equation 10 below.

$$
F_{i}=f(I V 1, I V 2, I V 3, . ., I V n)
$$

Where $\mathrm{F}_{\mathrm{i}}$ is component $\mathrm{i}$, and IV is the indicator variable for factor $\mathrm{I}$ for $\mathrm{i}=1,2,3 \ldots \mathrm{n}$.

Using Barlet scoring formulae (1937), then the Resilience components are estimated as:

$$
F_{i}=\left(\partial_{1} \mathrm{IV} 1+\partial_{2} \mathrm{IV} 2+\cdots+\partial_{n} \mathrm{IVn}\right) / \mathrm{n}
$$

Where $F_{i}$ is resilience component factor $i, I V$ is the indicator variable for factor $i$ for $i=1,2,3 \ldots . n$ and $\partial_{1}$ factor loading variance.

These factors combined gave the algebraic expression to resilience as:

$$
\mathrm{RI}=\partial_{1} \mathrm{ABSi}+\partial_{1} \mathrm{IFA}+\partial_{1} \mathrm{AA}+\partial_{1} \mathrm{NAA}+\partial_{1} \mathrm{~S}+\partial_{1} \mathrm{AC} \partial_{1} \mathrm{SSN}
$$

Where RI is resilience, ABS is Basic Services Access, A is asset, AC is the adaptive capacity, SSN represents social safety nets and $\mathrm{S}$ is stability.

\subsection{Variables and Units of Measurement}

This study used principal component analysis (PCA) on tropical livestock unit, calculated as 250 kilograms of grain to an animal, expenditures, income, food storage lifespan and number of hectares of land used for farming [20,21, 11]. The rationale of choosing these variables is explained below.

1) Food cost- This is the money spent buying food. A household that spends much on food signifies wealthy household, though this may be linked to lack of enough food productions

2) Income-This is the total earning of a household. Households with much earnings are more resilient compared to low earning

3) Land used for farming-This is the number of farms a household uses to produce or being used for production purposes. The more the number of farms, the more the food or income produced for a given household hence increasing food security

4) Livestock owned-This is the number of livestock owned (Tropical Livestock Units). The more the assets owned by a household, the more resilient the household is.

5) Stock last-The bigger the stock, the longer it lasts. A household with large stock is more resilient compared to a household with less stock hence less resilient.

\section{Results}

The study is aimed at assessing the coping, prediction and recuperation mechanisms from the pressures and shocks of at-risk households in Turkana County. This is done by establishing the key determinants of livelihood and coping strategies. The study also using the RIMA model estimated overall resilience index of Turkana county. The analysis of the data was done using STATA version 13. The results are discussed in the following sections.

\subsection{Income and Food (AIF)}

The majority $(67.3 \%)$ of the households living in Turkana County is falling in either poor or borderline food consumption categories. Approximately $32.7 \%$ households are within the acceptable food consumption score. The farming group showed the highest score at the borderline food consumption status followed by the fishing community. This is attributed to the prolonged dry seasons within the Turkana County resulting in poor crop performance. Pastoral, Agro-pastoral and urban populations showed acceptable food consumption as per livelihoods category analysis as shown in the figure 1 below. The food system comes from a multidimensional system that states that food system is made of at least two elements regardless of whether the supply is being made sure by the resource base or by the dependent socioeconomic component [22]

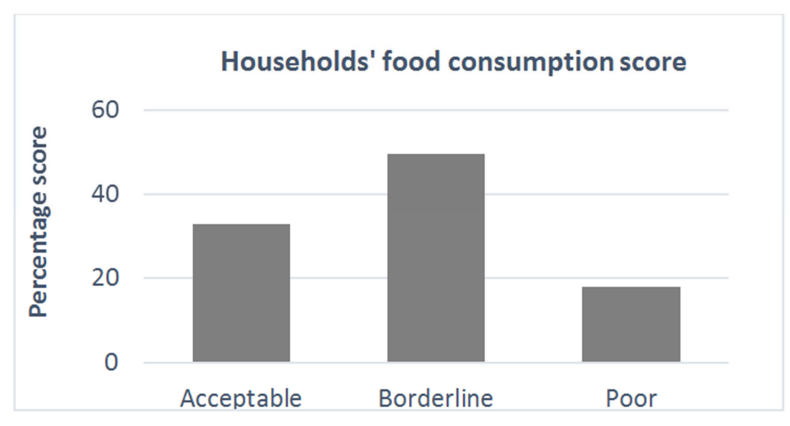

Figure 1. Food consumption Score. 


\subsection{Basic Services Access (ABS)}

Approximately $74 \%$ of the household surveyed use uncleared drinking water sources which is not fit for drinking as per the responses. Slightly above half of the households use Kerosene lamp and $36.2 \%$ use battery torch to provide light. Walking distance to school is approximately 25 minutes and majority (74\%) have access to school facilities. A greater percentage of the population $(85 \%)$ can access health facilities and services are rendered to them in these facilities.
Urban population has good access (90\%) compared to other groups with $74 \%, 63 \%$ and $58 \%$ for Agro-pastoral, pastoral and farmers respectively, while fishing community has the least access at $54 \%$. Basic services variables appeared to be negatively affected by the distance to the facilities and how many children within a given time drop out of school, whereas access to services such as credit, telephone and electricity showed positive influence across all the livelihood categories as shown in table 1 below.

Table 1. Basic services access estimation.

\begin{tabular}{lllllll}
\hline Variable & Turkana & Agro-Pastoralist & Fishing & Pastoralist & Farming & Urban \\
\hline Telephone & 0.4126 & 0.2618 & 0.3271 & 0.2129 & 0.3231 \\
Electricity & 0.4833 & 0.3902 & 0.6005 & 0.1512 & 0.3782 \\
Water access & -0.3523 & -0.4389 & -0.0415 & -0.5705 & -0.4198 \\
Work distance & -0.0321 & -0.2346 & 0.1129 & -0.3635 & 0.6428 \\
School dropout & -0.4462 & 0.3863 & 0.5231 & 0.6231 & 0.0394 \\
Credit access & 0.0356 & 0.3253 & 0.2569 & 0.1563 & 0.213 \\
\hline
\end{tabular}

\subsection{Agricultural Assets (AA)}

About 40-100 livestock is owned by the younger age groups while the older age category (42-59 years) owns a fewer number compared to the later. 31-35 years old category, owns an average of 54 livestock, this could be attributed by the fact that the majority of youths in this category prefer to live in urban centers to look for jobs and if they do not succeed, they go back to do livestock keeping hence the surge in the number of livestock between 36-40 years of age category. Hence, from the study findings, age is a contributing factor in the decision to either do pastoral or Agro-pastoral livelihood strategies. From the Table 2 below, Agro-pastoral, pastoral and framing groups value agricultural assets as compared to urban and fishing communities. These are due to the obvious fact that they use these assets a lot to earn a living.

Table 2. Agricultural Assets estimate (Ksh).

\begin{tabular}{llllll}
\hline Variable & Turkana & Agro-Pastoralist & Fishing & Pastoralist & Frban \\
\hline AA & $5,529.4$ & $9,397.8$ & $2,341.1$ & $6,316.9$ & $4,700.4$ \\
\hline
\end{tabular}

\subsection{Non-agricultural Assets (NAA)}

From the results, NAA seemed to be more relevant to urban and fishing population categories as opposed to another livelihood groups. It, however seemed less relevant to Pastoral and Agro-pastoral groups as indicated in the table 3 below probably because of the nature they are more focused on the Agricultural aspect of the income generating activities.

Table 3. Non-agricultural assets average estimate value.

\begin{tabular}{lllllll}
\hline Variable & Turkana & Agro-Pastoralist & Fishing & Pastoralist & Urban & Farming \\
\hline NAA & 4,218 & 3,362 & 5,192 & 2,761 & 4,316 & 6,236 \\
\hline
\end{tabular}

\subsection{Social Safety Nets}

These include factors such as money remitted from other countries, any transfers and charity support from NGOs or government. They are mainly more important to vulnerable poor households. In the study, these values were standardized and a zero mean and 1 as the variance was obtained thereafter factor analysis was conducted. Most of the poor households in urban areas showed a higher access to social safety nets compared to the pastoral and Agro-pastoral communities. This could be associated with accessibility to such kind of services compared to pastoral and Agro-pastoral communities who are mainly in the rural areas where access could be difficult during such times.

Table 4. Social Safety Nets total value (Kshs).

\begin{tabular}{llllll}
\hline Variable & Turkana & Agro-Pastoralist & Fishing & Pastoralist & Farming \\
\hline SSN & 117.1 & 31.8 & 45.6 & 24.2 & 42.6 \\
\hline
\end{tabular}

\subsection{Stability (S)}

Turkana experiences mostly weather and inflation related shocks. Weather shocks experience is mainly flooding and droughts whereas inflation related shocks include high food prices, high input prices, the death of breadwinner and 
inability to purchase food. Approximately $40 \%$ indicated to have experience at least one whether shock. Weather shocks bring about factors such as crop and livestock diseases, poor performance in crop production and loss or damage of assets. More than half (55\%) of the respondents stated that they have these factors related to weather shocks while $42 \%$ have experienced inflation related shocks. Other types of shocks were not rampant in the county, but about $10 \%$ of the surveyed households reported to have experienced illness, clashes and political related shocks. When a shock occurs, households are the central decision-making units (consumption smoothing, asset selling, livelihood strategies choice, coping strategies adoption) and the node of interactions with institutions as well as with both formal and informal social networks [23].
Table 5. Number of shocks experienced between Mid 2015-Mid 2016.

\begin{tabular}{|c|c|c|c|c|c|c|c|}
\hline \multirow{2}{*}{ Shock type } & \multicolumn{7}{|c|}{ Number of shocks } \\
\hline & $\mathbf{0}$ & 1 & 2 & 3 & 4 & 5 & Total \\
\hline Weather & 12 & 6.1 & 38.1 & 43 & 0.7 & 0.1 & 100 \\
\hline Agriculture & 6.2 & 13.2 & 34 & 25.3 & 16.2 & 5.1 & 100 \\
\hline Income & 2.4 & 19.2 & 39.5 & 27.2 & 7.4 & 4.3 & 100 \\
\hline
\end{tabular}

As can be seen from the table 6 below, Turkana County experiences all the types of shocks at above average levels (greater than 0.5 thresholds). Animal shock recorded the highest value of 0.7794 while shocks attributed from crops accounted for 0.5409. As expected, pastoral and Agro-pastoral categories recorded the highest score in terms of animal shock while crop shock is highest among the farmers and the Agropastoral groups. Urban categories experience other socks compared to pastoral, Agro pastoral and fishing categories

Table 6. Stability component estimate.

\begin{tabular}{lllllll}
\hline Variable & Turkana & Agro-Pastoralist & Fishing & Pastoralist & Farming & Urban \\
\hline Shocks & 0.7583 & 0.5416 & 0.545 & 0.5148 & 0.5125 \\
Animal shock & 0.7794 & 0.7682 & 0.2923 & 0.9901 & 0.5832 \\
Other shocks & 0.5728 & 0.6631 & 0.7645 & 0.5126 & 0.6871 \\
Crop shock & 0.5409 & 0.7788 & 0.6071 & 0.5913 & 0.7857 \\
\hline
\end{tabular}

\subsection{Adaptive Capacity}

Urban population is more able to cope when a shock occurs. Farmers and pastoral have the least way to cope when a shock occurs. This could be because they rely on subsistence farming and their livestock, hence when a shock occurs, they have nothing to leave in the store. During a disaster, poorer and less fortunate household, use of all the available resources i.e livestock and other assets that are functional to their livelihood activities thus reducing their chances to fall in poverty trap according to [24]. Urban population has better access to employment followed by fishing categories while pastoral have the least access to employment. Better access to diversity, education and food ratio was also better in the urban group as shown in the table 7 below. $86.3 \%$ and $66.91 \%$ of the Pastoral and Agropastoral households respectively move with their livestock to areas where they can get water and pasture for their animals. [25] study stated that Migration or relocation of the households, often referred to as maladaptive strategies, allow households to seek new economic and social opportunities elsewhere. In contrast, the migration of single household's members is functional to supplement standard incomes with individual remittances and allows members to divide the household's assets in larger shares. Pastoral groups may at times relocate to Agro-pastoral areas to look for the crop remains for the animals. In-kind assistance from well-off relatives, dividing meals amongst their counterparts, ensuring that children, aged persons and sick people get meals first compared to the remaining categories, sourcing for grass, firewood and wild fruits for sale, relocating to do fishing in the coastal areas, slaughter weak emaciated animals for food are some of the survival strategies used during calamities.

Table 7. Adaptive capacity estimate.

\begin{tabular}{lllllll}
\hline Variable & Turkana & Agro-Pastoralist & Fishing & Pastoralist & Farming & Urban \\
\hline Employment & 0.2245 & 0.2508 & 0.3404 & 0.2213 & 0.2419 \\
Diversity & 0.1513 & 0.2934 & 0.287 & 0.2301 & 0.2945 \\
Education & 0.1437 & 0.4671 & 0.356 & 0.356 & 0.4728 \\
Food ratio & -0.7832 & -0.7692 & -0.6953 & -0.6953 & 0.5896 & -0.5456 \\
\hline
\end{tabular}

\subsection{Resilience Index}

Turkana County scores resilience of 0 . 0457. The computed difference index among the livelihood groups and the overall resilience index showed that urban group is more resilient at 0.14 while fishing community are the least resilient at-0.2452. Agro-pastoralists, pastoral and farmers recorded $0.1121,0.1025$ and-0.1246 respectively as illustrated in the table 8 below. The negative shows low resilience score. Urban group could be more resilient due to the accessibility of infrastructure, services, adaptive capacity as well as sustainability. This is as a result of most of the resources being concentrated within the urban set up compared to rural areas. 
Table 8. Resilience index per livelihood group.

\begin{tabular}{ll}
\hline Livelihood group & Resilience index \\
\hline Agro-Pastoralist & 0.1121 \\
Fishing & -0.2452 \\
Pastoralist & 0.1025 \\
Farming & -0.1246 \\
Urban & 0.14002 \\
\hline
\end{tabular}

The sub-county index showed that Turkana central had the highest resilience index of 0.83 while Turkana North showed the least resilience of- 0.64 as can be seen from the Figure 2 below. High record to basic services access and income shows good resilience levels. There was the low level of adaptive capacity in Turkana County, which raises a concern. The difference in resilience index from sub-county to subcounty is attributed to basic services access, income and adaptive capacity. This depends on livelihood strategy as well as geographical distribution. Turkana central high resilience index, for example, could be attributed to Lodwar town, hence more economic activities, thus better income sources and adaptive capacity. Turkana North with the lowest resilience index score are mainly fishers' hence low-income source, Social Safety Nets and stability. The resilience index was obtained through factor analysis and iterated principal factor method to re-estimates commonalities iteratively.

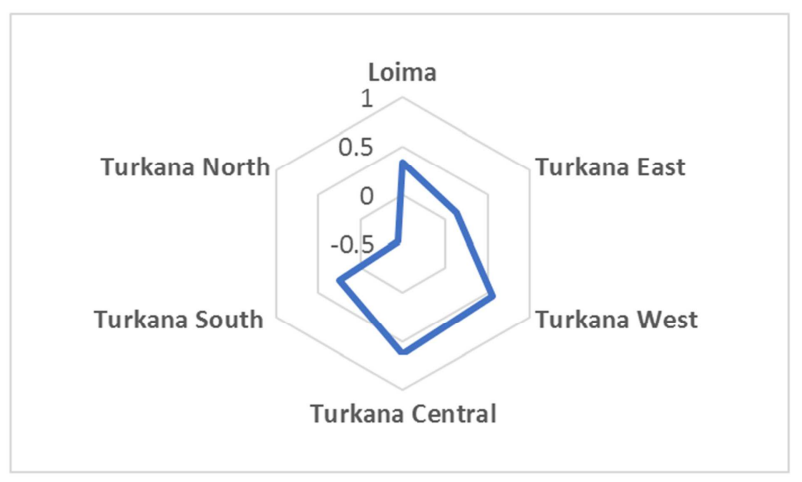

Figure 2. Resilience index by sub-cunty.

As can be seen in the figure 3 below, urban livelihood group recorded high scores resilience index with respect to access to basic services, capacity to adapt after a crisis occurs, access to food and income as well as ownership of Non-agricultural assets $(0.5301,0.5698,0.6373$, and 0.5753 respectively) while Agro-pastoral group showed highest (0.6478) contribution through Agricultural Assets to resilience index followed by pastoral $(0.5542)$ and farming groups $(0.5364)$. The results illustrate that Turkana County has an average resilience level. Even though the resilient levels are average, there are still households within the livelihood groups with low resilient levels because of inequality among the different livelihood groups. Across the livelihood groups, urban category showed the most inequality distribution, whereas pastoral and Agro-pastoral showed a more equally distributed resilience though below average level. This implies that the pastoral and Agro pastoral communities need special attention to help recover incase on a shock and able to adapt whenever a disaster occurs.

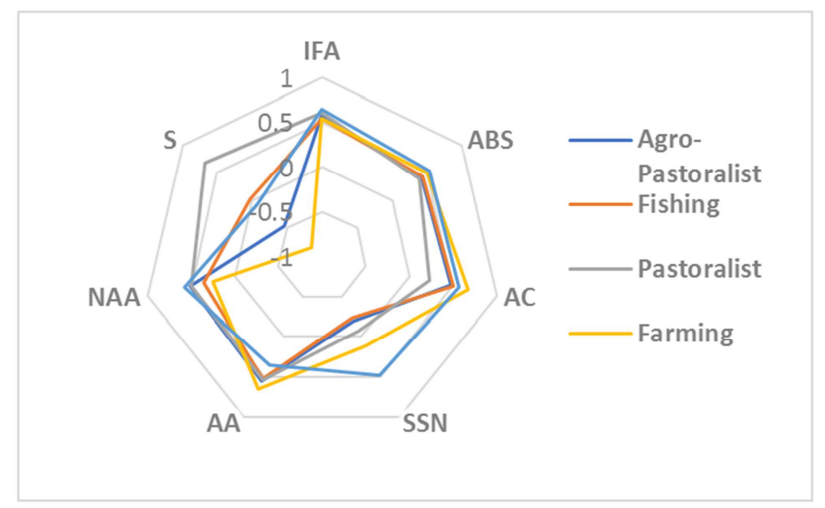

Figure 3. Resilience index by components and livelihood groups.

Turkana west showed the highest score in in resilience index, under access to food and income at 0.578 and stability (0.1953), while the least score was recorded in Loima, Turkana East, Turkana Central, Turkana south and Turkana North had 0.5678, $0.5621,0.3567,0.3345$ and- 0.3456 respectively. Turkana south demonstrated the highest score (0.5789) In terms of Basic Services access (ABS) and adaptive capacity (0.7234) while Turkana north, Turkana East, Turkana central and Turkana west had the least score $(0.1234,0.6723,0.4967$ and 0.1953$)$ as shown in the figure 4 below.

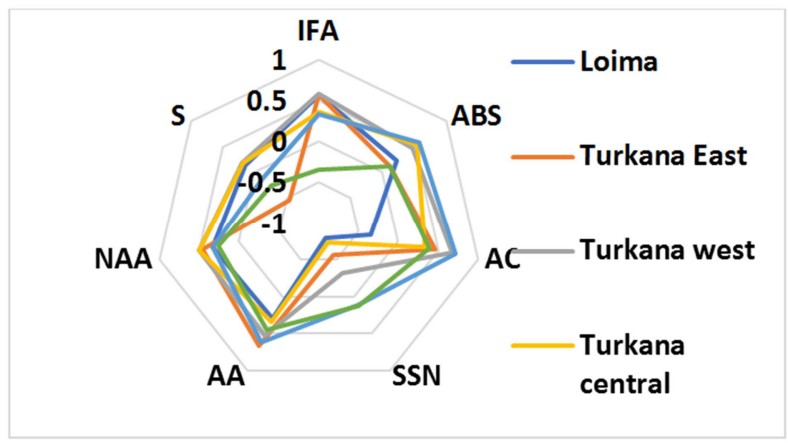

Figure 4. Resilience component by sub-county.

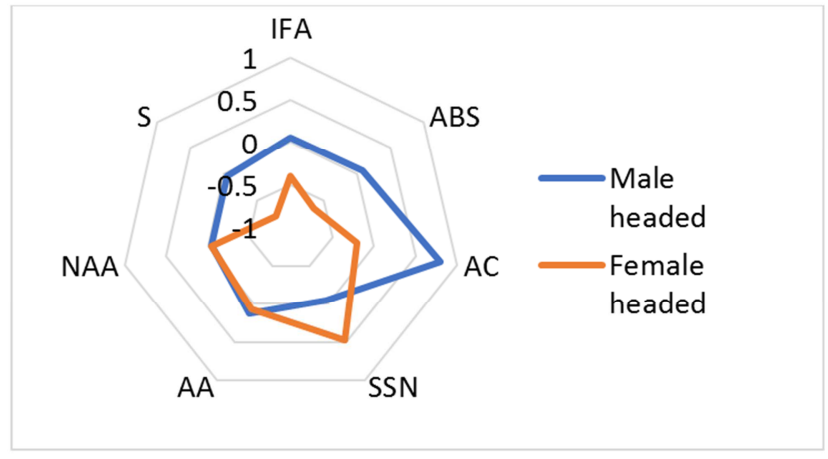

Figure 5. Resilience component by household head.

In Kenya, gender differences are normally considered a key factor that contributes to the role of men and women in terms of assets, education, economic opportunities, social protection schemes and decision-making process. The 
analysis illustrated that gender differences affects the resilience score in Turkana. Further study on socio-economic individual data would help understand the dynamics. From the findings, female headed households are less resilient compared to the male headed households' counterparts as can be seen in figure 5 above. This extensive difference was noted in terms of land and agricultural assets. This could be attributed to higher education levels compared to female category, the capacity to access basic services, food and income access. However, female headed households recorded high scores in terms of social safety nets as the simple way female headed households can deal with a shock when it occurs.

Agricultural, Non-Agricultural assets and stability recorded less scores for female headed households

The t-tests conducted on the livelihood mean difference indicated that the differences in terms of resilience index for Agro-pastoral, pastoral, fishers and farmers are not significant. Access to basic services, food and income as well as adaptive capacity gave urban population a greater prowess in terms of resilience disparity compared to other groups. This was illustrated by the larger t-statistics value. The t-test illustrated no statistical significance between stability and social safety nets and different for each resilience component, for instance, female in farming recorded higher scores in terms of income and food access and males high scores in stability in an urban livelihood group.

Table 9. T-test statistics on Resilience variables.

\begin{tabular}{|c|c|c|c|c|c|c|}
\hline \multirow{2}{*}{\multicolumn{2}{|c|}{ Model }} & \multicolumn{2}{|c|}{ Unstandardized Coefficients } & \multirow{2}{*}{$\begin{array}{l}\text { Standardized Coefficients } \\
\text { Beta }\end{array}$} & \multirow{2}{*}{$\mathbf{T}$} & \multirow{2}{*}{ Sig. } \\
\hline & & B & Std. Error & & & \\
\hline \multirow{7}{*}{1} & (Constant) & -1.215 & 0.454 & & 1.68 & 0.025 \\
\hline & IFA & $-6.561 \mathrm{E}-02$ & 0.070 & -0.055 & 0.4614 & 0.000 \\
\hline & ABS & $6.749 \mathrm{E}-03$ & 0.001 & 0.549 & 1.5701 & 0.000 \\
\hline & $\mathrm{AC}$ & 3.374E-03 & 0.000 & 0.456 & 2.954 & 0.001 \\
\hline & SSN & $-2.353 \mathrm{E}-03$ & 0.382 & -0.243 & -4.814 & 0.033 \\
\hline & AA & -1.466 & 0.537 & -0.438 & 1.59 & 0.000 \\
\hline & $\mathrm{S}$ & 1.456 & 0.321 & 0.290 & -1.358 & 0.034 \\
\hline
\end{tabular}

To compare the statistical significance between the livelihood groups and variables of resilience, Multivariate analysis of variance (MANOVA) statistical test for comparing multivariate means of several groups was used.

Table 10. MANOVA test statistics on livelihoods.

\begin{tabular}{lllllll}
\hline Source & & Statistics & df & F (df1, df2) & F & Prob>F \\
\hline Group & W & 0.9872 & 6 & 27,398 & 1.34 & 0.2341 \\
& P & 0.0134 & & 27,396 & 1.22 & 0.3421 \\
& L & 0.0234 & & 27,394 & 1.11 & 0.3245 \\
& R & 0.0456 & & 24,388 & 2.34 & 0.0012 \\
Residual & & 1673 & & & & \\
Total & & 1568 & & & & \\
\hline
\end{tabular}

$\mathrm{W}=$ Wilks' lambda $\mathrm{L}=$ Lawley-Hotteling trace

$\mathrm{P}=$ Pillai's trace $\mathrm{R}=$ Roy's largest root

From the findings, the multivariate tests Wilks' lambda, Pillai's trace, Lawley-Hotteling trace, Roy's largest root, indicate that there are differences in resilience index within each livelihood categories. This illustrates that there are one or more differences among the mean vectors for the livelihood groups. From the findings, p-values are less than 0.05 . This implies that the resilience index is different across the livelihood groups as shown in the table 9 above. The multivariate R-squared for this model is about $93.72 \%$, which is relatively strong.

\section{Conclusion}

From the findings, the resilience index score was recorded as 0.0457 . Livelihoods categories were found to be more relevant in determining the resilience index of households in
Turkana county and that gender is as well an important factor in determining resilience. Compared to the male headed households, female headed households are less resilient whenever faced with a shock. This is attributed to the fact that male headed households have easy access to credit, land, social services and diversified social networks.

The results also indicated that the urban category is more resilient (0.14) compared to other livelihood categories. Social safety net participation index and social support gave lowest and low scores respectively as per the low values of formal and informal money transfers. To correct this trend, state and nonstate actors can focus on increasing agricultural and nonagricultural income source programs, hence reducing constraints as a result of credit/debit. As per the findings, in the stressed seasons, many pastoral $(86.3 \%)$ and Agro-pastoral families (62.1\%) migrate to the areas where they can get pasture and water to their animals while farmers and fishing communities relocate to where they can avoid being hit by drought or flood. Household, who will not manage to migrate suffer from malnutrition in children and mothers due to lack of enough nutrients in the food consumed. In terms of the main priority areas to concentrate on, the study findings showed that water facilities, education and health services, job opportunities, income generation activities, food and nutrition and farming equipment and technology need more attention. The findings also showed that households who receives support from relatives, food and nutritional support, health support and contributions by well-wishers have more ability to recover during or after a shock occurs.

Access to market have a negative influence on the decision of a given household in terms of the kind of livelihood group 
to indulge in within Turkana County. The market access rate of the residents of Turkana County stands at $79 \%$ as per the study. Many households prefer to be involved in agricultural livelihoods, but the other options are based on the distance they can walk to the nearest market facility. This implies that the chances of a given household indulging in different economic activity are more likely to reduce as the distance to the nearest marketplace increases. People who live near marketplaces have greater chances of engaging in more than one economic activity since it is more convenient to widen their income scope compared to those living far away from the market facility. Household members can also get a broker, wage laborers, does petty trade when they have access to near market. In addition to livelihoods strategies which affects resilience index and very important in terms of measuring resilience capacity of a given household, credit, social services, capacity to utilize available social networks, land ownership also contributes in analyzing resilience capacity.

From the results, Urban livelihood categories have more access to basic services which enables them to attain high scores in resilience as well as food consumption score compared to other livelihood categories. Household with better access to good health care services and educational facilities tend to have better capacity to adapt and bounce back whenever a crisis occurs as the shock impact is reduced hence resilience strength. With increased diversion in terms of livelihood activities and reduced dependency ratio, more resources are available hence increased income. This explains that resilience of each livelihood category is dependent on how various components contributes to the resilient capacity of a household as well as livelihood. For this study findings, urban group appeared to be more resilient as Agro-pastoralist and Farmers categories follow. Income level and basic services access for pastoral group was low more so in communities/villages normally worst hit by drought. Agrarian categories showed less gender disparity compared to urban counterparts. This could be attributed to the fact that they have better access to basic services, adaptive capacity and food which are as seen from the study key factors in determining resilience of a given livelihood group.

\section{References}

[1] Levin, S. A., et al. (1998), "Resilience in Natural and Socioeconomic Systems" Environment and Development Economics volume 3 No. 2, pp 222-35.

[2] Holling, C. S. (1996), "Engineering Resilience versus Ecological Resilience. In: Schulze, P. E., Ed., Engineering within Ecological Constraints", National Academy Press, Washington DC, pp 31-43.

[3] Pimm, S. (1984), "The complexity and satibility of ecosystem Nature", No. 307, pp. 321-326.

[4] Gallopin, G. C. (2006), "Linkages between vulnerability, resilience, and adaptive capacity", Global Environmental
Change, No. 16, pp. 293-303.

[5] Arthur, W. B. (1987), "Self-reinforcing mechanisms in economics". In P. Anderson, K.

[6] Clark, N. and Juma, C. (1987), "Long-Run Economics: An Evolutionary Approach to Economic Growth", Pinter Publishers, London.

[7] David, P. A., (1985), "Clio and the Economics of QWERTY", American Economic Review Proceedings, Vol 75 No. 2, pp. 332-336.

[8] Chambers, R. and Conway, G. (1992),"Sustainable Rural Livelihoods: Practical Concepts for the 21st Century", Natural, Vol. 5 No. 16.

[9] Ashley, C. and Carney, D. (1999), "Sustainable Livelihoods Lessons from Early Experience", DFID, London.

[10] Lasse K. (2001), "The Sustainable Livelihood Approach to Poverty Reduction", Swedish international development cooperation agency.

[11] Demeke, M.; Kaitakire, F.; Tefera, N. (2017), " Building sustainable resilience for food security and livelihood dynamics: The Case of Farming Rural households in Ethiopia; Agricultural Development and Economics Division (ESA) ", Food and Agricultural Organization (FAO): Rome, Italy.

[12] Food Security Information Network (2014), "A Common Analytical Model for Resilience Measurement: Causal Framework and methodological options", World Food Programme, Technical Series No. 2.

[13] Alinovi, L.; D. Errico, M. Mane, and Romano, D. (2017), "Livelihoods Strategies and Household Resilience to Food Insecurity; An Empirical Analysis to Kenya", Food and Agriculture Organization of the United Nations (FAO).

[14] Gunderson LH, Holling CS, Light S. (1997), "Barriers and bridges to renewal of ecosystems and institutions", New York: Columbia University Press, Vol 3.

[15] Holling, C. S. (1973), "Resilience and Stability of Ecological Systems. Annual Review of Ecology, Evolution, and Systematics", Scientific Research Publishing, Vol 4, pp 1-23.

[16] FAO (2016), " Analyzing Resilience for better targeting and action; Resilience Index Measurement and Analysis-II", Food and Agriculture Organization of the United Nations (FAO).

[17] Connor, K. M., \& Davidson, J. R. T. (2003), "Development of a new resilience scale: The Connor-Davidson Resilience Scale (CDRISC) ", Depression and Anxiety, Vol 18, pp 76-82.

[18] Alinovi, L.; Mane, E.; and Romano, D. (2008), "Measuring household resilience to food insecurity: application to Palestinian households Agricultural Survey Methods"; John Wiley \& Sons Ltd, Chichester, UK.

[19] Jew, Cynthia L; Green, Kathy E; Kroger, Jane (1999), "Measurement and Evaluation in Counseling and Development", ProQuest Psychology Journals, Vol 32, No. 2; pg. 75.

[20] Lasse K. (2014), " The Sustainable Livelihood Approach to Poverty Reduction", Swedish international development cooperation agency.

[21] Lokosang L, Ramroop S, Hendriks SL. (2010), "Establishing a robust technique for monitoring and early warning of food insecurity in post-conflict Southern Sudan using ordinal logistic regression", Agrekon. Vol. 50, pp 101-30. 
[22] Edward Clay (2002), "Trade and Food Security: Conceptualizing the Linkages", Overseas Development Institute, London, UK, pp 11-12.

[23] Alinovi, L.; Mane, E.; and Romano, D. (2010), "Measuring Household Resilience to Food Insecurity: Application to Palestinian Households"; John Wiley \& Sons, Ltd, Chichester, UK.
[24] Hoddinott, J. (2006), "Shocks and their Consequences Across and Within Households in Rural Zimbabwe", Journal of Development Studies, Vol. 42, No. 2, 301-321.

[25] Ezra, Markos. (2001), "Ecological degradation, rural poverty, and migration in Ethiopia: A contextual analysis," New York: Population Council, working paper no. 149. 